\title{
Multiplier elements of innovation: towards an innovation model in the Mexican micro and small business
}

\author{
Elementos multiplicadores de la innovación: hacia un modelo de innovación en la \\ micro y pequeña empresa mexicana \\ Alejandra López-Salazar ${ }^{a}$, Gloria Leticia López-Salazar ${ }^{b}$ y Rubén Molina-Sánchez ${ }^{c}$
}

\begin{abstract}
:
Innovation is a fundamental strategy to generate and maintain a competitive position in the market, however, the companies' ability to generate innovations is not an easy task, as there are different factors that influence it. Although several innovation models have been developed, no ad hoc models have been proposed to the conditions of micro and small enterprise, nor the structural conditions in developing countries. Therefore, the objective of this research is to identify and analyze the most relevant management factors that drive innovation in Mexican micro and small business. To this end, 594 micro and small businesses from the Laja-Bajío region belonging to the commercial sector, service and manufacture, were surveyed. Semi-structured interviews were conducted to identify their needs on innovation generation. The results show that technology management, marketing strategies and human resources management are the key elements to drive innovation in the MSEs (Micro and Small enterprises).
\end{abstract}

Keywords:

Innovation, small businesses, technology management, marketing strategy, talent management

\section{Resumen:}

La innovación es una estrategia fundamental para generar y mantener una posición competitiva en el mercado, sin embargo, la habilidad de las empresas para generar innovaciones no es tarea sencilla ya que existen distintos factores que influyen en ella. A pesar de que se han desarrollado diversos modelos de innovación no se han propuesto modelos ad hoc a las condiciones de la micro y pequeña empresa ni a las condiciones estructurales de los países en desarrollo. Por lo tanto, el objetivo de esta investigación es identificar y analizar los factores gerenciales más relevantes que impulsan la innovación en la micro y pequeña empresa mexicana. Para ello se encuestaron 594 micro y pequeñas empresas de la región Laja-Bajío pertenecientes al sector comercial, servicio y manufcatura, por medio de entrevistas semi-estructuradas donde se les cuestionó sobre las necesidades que tienen para generar innovaciones en su empresa. Los resultados muestran que la gestión tecnológica, las estrategias de marketing y la gestión del recurso humanos son elementos fundamentales para impulsar la innovación en la Mype.

\section{Palabras Clave:}

Innovación, pequeñas empresas, gestión tecnológica, estrategia de marketing y dirección del talento humano

\section{Introduction}

In companies, innovation capacity is a key element in achieving sustainable competitive advantages in the long run, since it allows to use strategies that cannot be easily implemented by competitors and, at the same time, it is difficult for them to duplicate the benefits obtained with innovation. [1] It is through innovation that companies can

\footnotetext{
a Corresponding author, Universidad de Guanajuato, División de Ciencias Sociales y Administrativas Departamento de Finanzas y Administración, https://orcid.org/0000-0003-3927-9603 Email: lopez.alejandra@ugto.mx

b Universidad de Guanajuato, División de Ciencias Sociales y Administrativas Departamento de Finanzas y Administración, https://orcid.org/0000-0003-4424-128X, Email: gl.lopez@ugto.mx

Universidad de Guanajuato, División de Ciencias Sociales y Administrativas Departamento de Finanzas y Administración,
} https://orcid.org/0000-0001-6915-9122, Email: rmolina@ugto.mx 
be shielded or covered by competitors' efforts to gain a better position in the market, as they represent the proactive capacity of companies to use their resources. [2] Several authors highlight the positive impact of innovation on business performance (Hung \& Chou, 2013; Rubera \& Kirca, 2012), which has been evaluated in financial terms through indicators such as return on investment, profit growth, return on assets, sales growth and financial liquidity (Waleed, 2015; Prorokowski, 2014; Moghaddam, Imani, Erteza \& Setayeshi, 2013; Kostopoulos, Papalexandris, Papachroni \& loannou, 2011); but nonfinancial variables such as market share growth, customer satisfaction and staff turnover have also been used (Waleed, 2015; Fernandes, Ferreira \& Raposo, 2013; Goven, Muzaffer, Cengiz \& Pinar, 2012). What has become clear so far is that innovation is fundamental to the growth and success of companies, however, the process and the most relevant factors that drives innovation have not been understood yet, especially in micro and small business (MSEs), where factors like heterogeneity in its characteristics, the difficulty of obtaining information and informality in its processes, hinder its analysis. In this regard, it is important to propose innovation models focused on the reality of Mexican micro and small business, taking into consideration both, management and organizational factors which have the greatest impact on innovation. Therefore, as a first approach to develop an innovation model, the standpoint of this research is to identify and analyse the most relevant management factors that drive innovation in Mexican micro and small business. [3] [4] [5] [6] [7] [8] [9]

\section{Theoretical framework}

\section{Characteristics of an innovation model for Mexican MSEs}

The development of an innovation model should be based on the specific conditions of companies, at least in terms of their size. Large companies can attract human talent from anywhere in the world, can allocate financial resources for research and development activities, and have a long-term vision regarding earning yields. By contrast, small businesses are focused on the short term, do not have the financial support to make long term investments, their main concern is focused on how to increase sales, and MSEs do not have the structural conditions to drive innovation.

The innovations generated within the company are the result of an intentional effort, which is based on autonomous strategic behaviour or induced strategic behaviour (Burgelman, 1995 cited in Hitt, Ireland and Hoskisson, 2009). Due to the specific characteristics of small businesses, autonomous innovation becomes more relevant since generally, the owner or founder of the company is a fundamental part of the strategic direction of the business and therefore, he is a key individual who serves as the product champion. [10]

Ideally, the MSEs would be able to foster both, autonomous and induced innovation, however, the latter is more complex as it does not have a formalized decisionmaking system involving processes and procedures already standardized.

In addition, innovation in the MSEs is more focused on developing small incremental improvements to its current products, because they are generated in an evolutionary way through the knowledge of the market it serves, by the mastery of the production process it uses and by the hybrid strategy it pursues. Radical innovations have greater potential to generate growth in revenue and profits, and therefore it allows to achieve better performance than competitors, so it is much more complex for MSEs to generate technological advances involving new knowledge (Ahuja and Lampert, 2001), compared to larger companies. [11]

A model that drives innovation in the MSE should take into account that the planning function in these companies is almost non-existent at least in terms of the development of a formal plan that defines goals, objectives, strategies and actions. Therefore, more than defining a planning activity, the function should be directed towards analysing the business strategy that is being carried out and, the opportunities for improvement and innovation through technology. This involves defining projects to improve or create products, processes, commercialization, or management forms.

\section{Technology management, marketing strategy and human talent management: innovation multiplier elements}

There are three fundamental elements that must be considered in an innovation model of the Mexican MSEs: technological management, marketing strategy and direction of the human talent. While there are other organizational and external elements that need to be considered in an innovation model, the objective of this work is to deepen into the management factors that are critical for enhanced improvements and innovations in products, processes, markets, and organizational processes.

Technological Management ensures the development of internal improvements or innovations based on identifying, aligning, acquiring, assimilating, and maintaining the organization's technology, through technological surveillance, aligning the business strategy with technology, designing financing strategies for technological projects and the conditions generated to achieve individual and collective learning.

The SME's technology determines its ability to produce goods and services with the specifications and 
requirements that customer demands in terms of quality, costs, presentation, and volume. This implies optimization in both, production, and organizational processes (sales, warehouse, human resources, administrative) to achieve greater productivity.

Regarding technological management, technological surveillance becomes very relevant since it is a process where, the company is investigated, analysed and information on technical and technological advances are disseminated and that fact represent an opportunity or threat to the company (Martinet and Ribault, 1989 cited in Palop and Vicente, 1999).

This implies that MSEs must monitor scientific and technical advances, new technologies, to work on improvements and innovations related to product, service, manufacturing processes, developments in the raw material and its processing chain, as well as in information systems.

For companies, technological surveillance involves a) to conduct an analysis of patents and scientific publications, b) to carry out reengineering of competitors' products and, c) identifying technological capabilities of competitors and, comparing them with those of the company itself. This information on science and technology can be captured through direct observation of technology, linking with experts, online, at fairs and exhibitions, in scientific literature, in professional organizations and through benchmarking. [12] [13]

The marketing strategy also plays a key role in the innovation process. When companies define their business strategies and implement them properly, they lay the groundwork for innovation in their organizations and therefore increase sales. This means that MSEs must make good decisions regarding their product portfolio, market segmentation, brand positioning and marketing mix (product, price, distribution, promotion and people).

The demand for innovation is based on the company's knowledge of its customers. It is difficult to determine the changes the company should make in terms of product characteristics and attributes when the customer profile has not been studied. The company has managed to know the customer when it has the ability not only to meet their needs but to plan the changes that might improve their experience when consuming a product or service.

The third element refers to the direction of human talent as it has a great influence on innovation capacity, since employees are the ones who implement business strategies. The development of dynamic skills in staff should be a priority for small businesses, and this will be achieved when the company is committed with employee training, when it focuses on hiring specialized personnel in an area where the company needs improvement or does not have the knowledge to develop specific activities, and when the company emphasizes in a culture of exchanging information and dissemination knowledge.

Another important element is performance assessment because it allows to keep staff motivated and increase the chances of keeping them in the company. In this way, the MSEs must establish mechanisms to incentivize, reward and project the personal growth of employees, otherwise the conditions for working in a high-performance environment are not generated. Finally, it is relevant to critically analyse the organizational behaviour that defines how people unfold in their work environment, to detect the improvements that need to be implemented in terms of the characteristics, beliefs and attitudes that are intended to be generated to accomplish a culture of intraentrepreneurship.

\section{Methodology}

With the aim of analysing the importance of technological management, marketing strategy and human talent management in the innovation capacity of Mexican micro and small enterprises, 594 companies from the Laja-Bajío region belonging to eleven municipalities were surveyed. Table 1 shows the main characteristics of the sample in terms of size, economic sector, and permanence on the market.

\begin{tabular}{|c|c|c|}
\hline \multicolumn{2}{|c|}{ Indicators } & $\begin{array}{l}\text { Valid } \\
\text { Percentage }\end{array}$ \\
\hline \multicolumn{3}{|c|}{ Economic sector } \\
\hline & Manufacture & 10 \\
\hline & Commerce & 51 \\
\hline & Service & 39 \\
\hline \multicolumn{3}{|l|}{ Size } \\
\hline & Micro & 84 \\
\hline & Small & 10 \\
\hline \multicolumn{3}{|l|}{ Age } \\
\hline & Up to 10 years & 38 \\
\hline & 11 to 20 years & 31 \\
\hline & More than 20 years & 31 \\
\hline
\end{tabular}

Table 1. Sample characteristics.

Business owners and managers were interviewed using a semi-structured questionnaire with open questions to trigger the exchange of information about their innovation practices. The open questions that were asked were: Have you promoted innovation in the company? Why and how did you do it? and, what needs do you have to drive innovation in the company?

The interviews were recorded and transcribed to a word processor, and, with the responses obtained, a content 
analysis of each of the responses was performed, generating categories based on the interpretation of the speech.

\section{Results}

In relation to the analysis of the activities that drive innovation in MSEs, 69\% state that they do promote innovation in the company, mainly by products, machinery and / or forms of marketing. Efforts towards innovation are not related to the business sector (chi-square $p-0.390$ ) or to the company's age (chi-square $p-0.216$ ) but to the size of the company (chi-square $\mathrm{p}-0.002$ ). In the case of microenterprises, $65 \%$ of them promote innovation, small business $86.5 \%$ and the medium ones $94.1 \%$. This may be because, when a company grows, it usually has a greater provision of additional resources to drive innovation, either to incentivize staff, invest in improvements or starting new projects; In addition, larger companies serve, more demanding and changing markets by forcing them to improve their products, propose new services and products, at a lower cost.

When analysing testimonials about the companies' needs to drive innovation, there are three main elements highlighted, that is: marketing strategies, technology management and human resource management. However, administrative, financial, and fiscal advice is also considered as a driving factor in innovation, although its importance is minor.

\section{Marketing strategies}

Regarding marketing strategies, MSEs are aware of the importance of knowing the market to define strategies that improve the business image, product positioning, sales level, and market share. Here is a testimony that speaks of it:

In customer service, to know what the needs are and that customers will end up feeling satisfied (interview 48) (industry, production and dairy products sales, micro).

When the market is not properly studied, there are difficulties when positioning the products, as exposed by some companies that, even when they have managed to enter international markets, they have not dominated the domestic market because of a lack of knowledge and adaptation of marketing strategies, as expressed by these micro-enterprises:

... to start, in the way it has to reach the market, it is not yet well placed, and I would like to be taught on how to select the market well, to introduce it, it is sold in the municipality and some surroundings only, we are looking to see if we introduce it to stores like Soriana and SuSazón ... (interview 200) (industry, agroindustrial, micro-enterprise).

Fieldwork, I think is what we need because sometimes you think, "that's what the customer needs" and we are mistaken... (interview 250) (jewelry trade, microenterprise).

Branding is also a strategic task for the company, however, very few companies are at such level of development that they manage to design and position the product brand as they are generally focused on functional or operational strategies such as product distribution and promotion. It considers only the testimony of two micro companies that are concerned about the image of the company:

The bread brand and the bag were changed to get more attention (interview 407) (industry, services, micro).

Related to the corporate image responsible department (interview 292) (trade, groceries sales, microenterprise).

A large percentage of companies focus on improving the image in the way they display their products, the physical conditions of the shop and facilities in general, in such a way, they look more attractive to the customer.

The MSEs identify the need to generate an effective promotion strategy to achieve the sales proposed objectives. In this way, companies must define how they will carry out the promotion, that is, they must make decisions based on the customer type, product kind, that is to say, the information and the context required to be transmitted:

Perhaps in the matter of how to advertise more effectively, in the case of small businesses, how we could project ourselves (interview 90) (trade, groceries, microenterprise).

For the process of defining and implementing marketing strategies, there are techniques such as benchmarking that are used by SMEs to analyse and compare against the best practices of the most competitive companies. Likewise, benchmarking focuses on different aspects such as business practices, pricing, product and service innovations, promotional strategies, to name a few. Some testimonials are shown referring to benchmarking practices:

Which companies have better prices, what is new in the field. (interview 118) (trade, stationery, and gifts).

At the end of the day, companies always follow the leading company. Knowing the results of successful companies take for granted the process, time, and money. (interview 235) (services, lodging and food services, microenterprise). 
Therefore, it can be summarized that the design and implementation of the business strategies influence the innovation capacity of MSEs, which implies to define strategic aspects (definition of the product portfolio, market segment and brand positioning) as well as operational (marketing mix).

\section{Technology management}

The MSEs needs to identify the right technology based on the problem they are facing, and the improvements they need to implement. For example, there are companies that demonstrate the need of machinery to reduce specialized time and costs in their branch:

Maybe related to machinery, in the robotics and engineering area we have the knowledge there is a lot of machinery that reduces time and costs, when cutting both, paper and lamina (interview 9) (Industry, small business, manufacturing and assemblies of electrical transformers).

While several SMEs are clear about the type of technology they need, many others are unaware of the latest advances in the machinery they use, so they need to know the best available options on the market. This means that they do not yet establish mechanisms (even informally) to know the technology innovations available.

In this case, it would be related to machinery because I have some vision, but in this case, it is my opinion and maybe there is a better option but I do not know it (interview 77) (industry, microenterprise).

It also highlights the need to identify and incorporate new technology to the company with the intention of improving the service offered to the customer, either by the speed and effectiveness of the service or in the efficiency in the use of resources, as well as in, improving the quality of the products or services offered.

New technology to improve service (interview 522) (services, mechanical workshop, micro).

More than anything in technological advances because it is a key point for better quality and service (interview 571) (services, laboratories, micro).

Once the company identifies the technology it needs, it must have the resources to acquire it, either with its own funding or external financing. However, for SMEs this is a problem, as they generally do not have a financing and investment strategy that allows them to acquire the most advanced technology.

I like technological innovation very much but I do not have any of those means (interview 389) (services, service provider, microenterprise).
When companies manage to acquire the necessary technology, the company is required to go through a process of technological assimilation. The assimilation of new technology is the company's ability to make the most of it where you advance on the learning curve as time passes. This implies that companies have managed to adapt the technology to the specific process of the company making it as efficient as possible, due to the information and knowledge acquired. This is because the way in which the knowledge related to machinery usage and control has been documented and disseminated, the employee has been trained for its usage and kept up to date with the licensor (which happens in most cases for SMEs) regarding equipment improvements or forms of use.

In the use of new production technologies since there are currently the latest manufacturing processes that can make the company more efficient (interview 3) (manufacturing industry).

Finally, the machinery maintenance turns out to be an activity of great importance in the organization's productivity; however, despite the costs the company may incur when a machine stops working, the SME has difficulty performing preventive and corrective maintenance causing great losses in terms of costs, productivity, sales, and customer service. This is because most SMEs acquire dealer technology and they do not always have maintenance service insured.

Our machines require constant maintenance but above all, quality, there are no technicians suitable for both, preventive and corrective maintenance for photocopying and it is a key pillar in my business (interview 343) (trade, school stationery and office, microenterprise).

Therefore, it is concluded that the technological management in the MSEs requires five main functions: identification, alignment, acquisition, assimilation, and maintenance of the appropriate technology for the organization. Each of these functions are determined by different processes. In the case of the function of identifying the most suitable technology for the company, the technological surveillance process is essential to develop, maintain and strengthen competitive advantages.

\section{Human Resources Strategy}

According to the MSEs' testimonies, there is a strong need to receive training especially on technical and branchspecific aspects. For example, there are butcher shops that want to know more about the new cuts of meat they have to offer to customers; gyms that want to train in different sports or different types of exercises; locksmith's shops that require new security systems; to name a few. 
Another type of training that is commonly required is the one that allows to know in depth, the products offered by the company, to guide the customer in their purchasing process managing to differentiate in consumer service, as shown by the following testimonials:

In regards of tires' knowledge, to reinforce a little what we already know. Reinforce technology on each tire (interview 142) (trade, tires and suspension, microenterprise).

Well, in everything that is new, coaching must be given to guide people and tell them what benefits they will have (interview 122) (trade, white line, microenterprise).

While the use of ICT in small business is becoming more common, there are still companies that have failed to standardize technological knowledge among their employees, diminishing the possibility of standardizing the service offered.

In technology, sometimes many of us are not close to electronics, most of the clinical staff is very young, I mean, they have less than 7 years of experience in their positions; on the other hand, some of us have more years of experience, especially in technology (interview163) (services, health).

Maybe in new technology, people training to motivate them, to reach self-improvement, so they think "if they do well, I'll do well', is in both ways; often employees think employers do nothing (interview 166) (services, restaurant, microenterprise).

On the other hand, the conflicts that arise within the staff, affect the development of the company's day-to-day activities and consequently its performance; however, the MSE is more concerned about generating sales and use to set aside the human resource management, leading to strong problems with the staff.

I believe in the human development part, one of the things we are dealing with, is the personnel turnover; since Guanajuato is an entity with a strong emigration rate to the United States, so the personnel turnover is very high. We can have the best quality system in the world or the best facilities, but without people things simply do not work out. So, it must be something about human development, motivation because it's hard to retain people (interview 80 ) (industry, plastic injection). In the employee management because I do have problems (interview 291) (trade, tortillas, microenterprise).

Regarding staff management, the third element that influences innovation is individual and organizational behaviour. The leadership styles, the company's conditions for intra-entrepreneurship, the attitudes and perceptions of individuals and work teams, conflict management, and interpersonal and intergroup interactions are the elements that define how staff behave in the work environment.

Based on the results analysed, we can conclude that regarding the innovation culture of Mexican micro and small business, the predominant role of technology management, marketing strategies and human resources management is confirmed (figure 1).

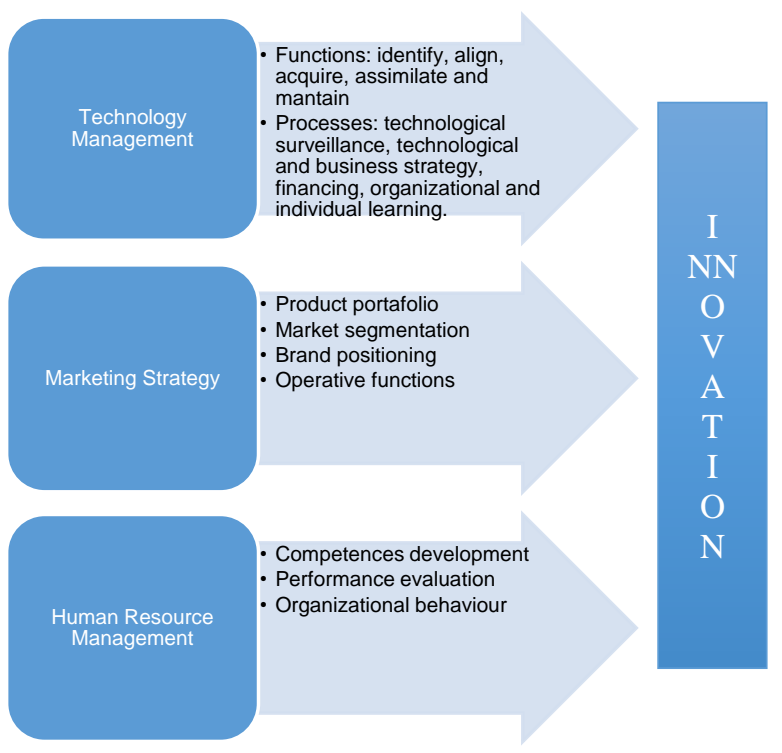

Figure 1. Innovation drivers for micro and small
businesses

\section{Conclusions}

The objective of this research is to identify and analyse the most relevant management factors that drive innovation in Mexican micro and small business. The results confirm that technology management, marketing strategies and human resources management are key elements in driving innovation in the MSEs. Regarding technological management, the results emphasize the importance of identifying technological upgrades and updates continuously, to access this technology, to define the project for improvement or innovation on the products or processes in which the new technology will be used as well as developing a funding plan. Marketing strategies take on great relevance in the MSEs innovation as market knowledge allows you to identify specific customer needs and define the characteristics the product or service does or has. This is possible thanks to direct communication with the customer which allows to understand their demands and needs almost immediately. This means that the company has information about trends and can 
prepare to attend changes in preferences quickly. Regarding human resource management, MSEs focuses on employee training and staff turnover issues, setting aside performance assessment. Having employee performance information allows to provide feedback to the staff about their performance, to incentivize a better performance, to assess their capabilities for future promotions, to award them, to determine their salary, and to detect training needs.

What is clear is that the variables that stimulate innovation are: the company's commitment to offer training and development to the staff, the safety offered to employees in their positions, and finally, the innovative behaviour. Therefore, the MSEs innovation models design should include the most relevant management factors in technology management capabilities, marketing strategy design and human resources. This is a first approach to build an innovation model.

Future work should discuss organizational aspects such as organizational learning, social capital, and organizational structure, as well as external factors that affect the path to innovation such as macroeconomic stability, labour, financial and asset market efficiency, as well as the country's legal and institutional framework. And of course, incorporating the entrepreneur profile as a fundamental element since innovative capacity requires a very clear and determined vision to generate the process of change.

\section{References}

[1] Barney, J. (1991). Firm Resource and Sustained Competitive Advantage, Journal of Management, 17(1), 99-120.

[2] Diercikx, I. y Cool, K. (1989). Asset Stock Accumulation and Sustaintability of Competitive Advantage. Management Science, 35 (12), 1504-1511.

[3] Hung, K. y Chou, C. (2013). The impact of open innovation on firm performance: The moderating effect of internal $\mathrm{R} \& \mathrm{D}$ and environmental turbulence. Technovation, 33 (10-11), 360-380.

[4] Waleed, O. (2015). Innovative behavior and venture performance of SMEs. European Journal of Innovation Management, 18 (2), 195 - 217.

[5] Prorokowski, L. (2014). Is investing in innovation an effective strategy in times of crisis? Some evidence from Poland, Innovation, 16 (1), 32 52

[6] Moghaddam, A., Imani, Y., Erteza, N. y Setayeshi, L. (2013). Mediating role of innovation $\&$ market- orientation in the relationship between knowledge management \& financial performance: a case study of small $\&$ enterprereur business. Interdisciplinary journal of contemporary research in business, 5(3).

[7] Kostopoulos, K., Papalexandris, A., Papachroni, M. y Loannou G. (2011). Absorptive capacity, innovation, and financial performance. Journal of Business Research, 64, 1335-1343.
[8] Fernandes, C., Ferreira, J. y Raposo, M. (2013). Drivers to firm innovation and their effects on performance: an international comparison. Springer Science+Business Media New York. 9. pp. 557580 .

[9] Güven, A., Muzaffer, B., Cengiz, Y. y Pinar, B. (2012). How does innovativeness yield superior firm performance? The role of marketing effectiveness. Innovation: Management, Policy \& Practice, 14 (1), 107128.

[10] Hitt, M., Ireland, R. y Hoskisson, R. (2008). Administración Estratégica. Competitividad y globalización. México: CENGAGE Learning.

[11] Ahuja, G. y Lampert, M.(2001). Entrepreneurship in the large corporation: A longitudinal study of how established firms create breakthrough inventions, Strategic Management Journal, 22, número especial, 521-543.

[13] Pedroza, A. (2013). Inteligencia Competitiva. En Pedroza, A., Garrido, L., López, C., Ortiz, V. Y Ortiz, J. (2013). Innovación y tecnología en la empresa. México: Ed. ITESO y ACACIA.

[13] Rubera, G. y Kirca, A (2012) Firm Innovativeness and Its Performance Outcomes: A Meta-Analytic Review and Theoretical Integration. Journal of Marketing, 76 (3), 130-147. 